\title{
Development of Surface Plasmon Resonance (SPR) Based Immuno-Sensing System for Detection of Fungal Teliospores of Karnal Bunt (Tilletia Indica), a Quarantined Disease of Wheat
}

Sadhna Singh', Manoj Singh'1, Gohar Taj', Sanjay Gupta² and Anil Kumar*

${ }^{1}$ Department of Molecular Biology \& Genetic Engineering, College of Basic Sciences \& Humanities, G. B. Pant University of Agriculture \& Technology, Pantnagar Uttaranchal, India

${ }^{2}$ Department of Biotechnology, SBS PG Institute of Biomedical Sciences, Balawala, Dehradun, Uttarakhand, India

\begin{abstract}
This paper first time describes Surface Plasmon Resonance (SPR) based immuno-sensing system for detection of fungal teliospores of Karnal Bunt (KB) disease of wheat incited by Tilletia indica. The results of present study were compared with the results of lab scale ELISA developed earlier in our lab. The approach involves the use of a rabbit polyclonal (anti-teliospore) antibody and a SPR sensor for label-free detection of teliospores from the model organism Tilletia indica. When the interaction between binder (anti-teliospore antibody) and teliosporic antigen(s) as analyte occurs at the sensor surface, a sensorgram was obtained in real time by plotting the signal against time. Under optimised assay conditions as few as 5 teliospores were detected by ELISA which justifies the greater affinity of raised anti-teliospore antibodies for its antigen. The sensitivity of each immunosensor constructed with the different amounts of antigen solution is determined by sensogram analysis showed detection sensitivity as low as $625 \mathrm{pg}$ equivalent to 2.5 teliospores over the sensor surface by getting an angle of dip indicating greater affinity of raised anti-teliospore antibodies. Thus, SPR based affinity sensor showed higher sensitivity due to greater signal response. The results of cross reactivity studies using different related fungal spores/teliospores showed almost differential SPR response indicating cross reaction using immunosensing system. The cross-reactivity of anti-teliospore antibodies with related fungal spores/teliospores can be explained due to its polyclonal nature and also due to antigenic homology amongst pathogens used in present study.
\end{abstract}

Keywords: Immunodiagnostics; Karnal bunt; Tilletia indica; Surface plasmon resonance; Teliospore; Fungal diagnostics

Abbreviation: KB: Karnal Bunt; SPR: Surface Plasmon Resonance

\section{Introduction}

Wheat (Triticum aestivum) is one of the most important food crops of the world. In India, the wheat is affected by a number of diseases. Out of which rusts, smuts, powdery mildew, loose smut, leaf blight and Karnal bunt continue to be the limiting factor in increasing wheat yield. Amongst these diseases, Karnal bunt is the major disease of wheat (Triticum aestivum) and caused by the sporadic fungus, Tilletia indica (Syn Neovosia indica). Karnal Bunt (KB), also called partial bunt, was first detected at Karnal (Haryana) by Mitra [1], and hence the name. It also affects durum wheat and triticale which result in reduced crop yield and poor grain quality. It gives off a fishy odour due to the presence of trimethylamine secreted by teliospores. It occurs frequently in the north-western plains and Tarai regions of Himachal Pradesh, Punjab, Uttar Pradesh and Uttarakhand states of India. Uttarakhand Tarai- a KB prone area is fulfilling the demand of about $40 \%$ of the total need of wheat seed in India as well as neighboring countries. $\mathrm{KB}$ is an economically important disease and pathogen is placed as a quarantine pest. Contamination of wheat grains with Karnal bunted grains has emerged as a serious non-tariff barrier in the international trade of wheat. Hence, it has implication in seed certification aspects. As at present none of the control measures had been proven to be satisfactory for the disease management, hence it becomes inevitable to develop suitable detection system for seed health testing of wheat lots for strengthening seed certification and plant quarantine measures [2].

The molecular and immunological methods developed in our lab are quite useful for both differentiation of fungal species and detection of KB disease. Although nucleic acid-based detection systems are more specific for individual species [3], antibody-based methods are often conducive to rapid analysis, since limited sample extraction is needed. The major disadvantages of nucleic acid methods in seed health testing becomes evident when it is necessary to determine the level of infection (quantification) in the seed sample. Significant progress has been made in our lab to develop the rapid formats for immunodiagnosis of $\mathrm{KB}$ teliospores by using high titre polyclonal antibody probes raised against intact teliospores in New Zealand white rabbits $[4,5]$. The developed immunodiagnostic formats viz. Seed Immunoblot Binding Assay (SIBA), indirect immunofluorescent staining tests, dyed latex bead agglutination assay and immuno-dipstick assay can be successfully employed for the sensitive detection of seed borne inoculum of the fungus present either in bunted seeds or as loose teliospores on the seed surface [5-8].

The Surface Plasmon Resonance (SPR) sensor is used for labelfree detection and real-time monitoring. Their simplicity and sensitivity make biosensors an effective means of disease diagnosis and monitoring [9]. In particular, biosensors based on antibodies

${ }^{*}$ Corresponding author: Dr. Anil Kumar, Professor \& Head, Department of Molecular Biology \& Genetic Engineering, College of Basic Sciences \& Humanities, G.B. Pant University of Agriculture \& Technology, Pantnagar-263 145, U.S. Nagar, Uttaranchal, India, E-mail: ak_gupta2k@rediffmail.com

Received September 05, 2012; Accepted October 15, 2012; Published October 17,2012

Citation: Singh S, Singh M, Taj G, Gupta S, Kumar A (2012) Development of Surface Plasmon Resonance (SPR) Based Immuno-Sensing System for Detection of Fungal Teliospores of Karnal Bunt (Tilletia Indica), a Quarantined Disease of Wheat. J Biosens Bioelectron 3:125. doi:10.4172/2155-6210.1000125

Copyright: (c) 2012 Singh S, et al. This is an open-access article distributed under the terms of the Creative Commons Attribution License, which permits unrestricted use, distribution, and reproduction in any medium, provided the original author and source are credited. 
Citation: Singh S, Singh M, Taj G, Gupta S, Kumar A (2012) Development of Surface Plasmon Resonance (SPR) Based Immuno-Sensing System for Detection of Fungal Teliospores of Karnal Bunt (Tilletia Indica), a Quarantined Disease of Wheat. J Biosens Bioelectron 3:125. doi:10.4172/2155-6210.1000125

Page 2 of 8

are able to perform very specific analyses [10]. While highly specific and sensitive, biosensors based on antigen-antibody interactions (also called immunosensors) require an appropriate antibody (specific immunoprobe) in order to determine the correct identity of contaminating fungus. The shift of the resonance angle can be observed using the Surface Plasmon Resonance (SPR) technique, when the intended species is captured by the immobilized antibody on the sensor surface $[11,12]$. SPR based immunosensor can be used for detection of fungal teliospores or its antigens in a fully automated manner with high sensitivity, more quickly, cheaper, and a large number of samples can be analyzed.

Therefore, in this paper attempts were made to develop SPR immunosensor for detection of $\mathrm{KB}$ in order to identify the presence of teliospores in wheat lots for the purpose of seed certification lab and plant quarantine regulation.

\section{Materials and Methods}

\section{Chemicals and reagents}

$\mathrm{N}$-(3-dimethylaminopropyl)-N-ethylcarbodiimide hydrochloride (EDAC) and Sodium Dodecyl Sulphate (SDS) were obtained from Bio Basic. N-hydroxysuccinimide (NHS) and 11-Mercaptoundecanoic Acid (11-MUA) were obtained from Aldrich. Bovine Serum Albumin (BSA) was purchased from Himedia. Ethanol and hydrochloric acid ( $\mathrm{HCl})$ were obtained from S D fine-chem limited, Mumbai. Ethanolamine was purchased from Lifetech. Sodium hydroxide $(\mathrm{NaOH})$ was purchased from SRL. Alkaline phosphatase-conjugated goat anti-rabbit gamma globulin was obtained from Bangalore Genei, Bangalore and p-nitro phenyl phosphate sodium salt was purchased from Sigma Chemical Co., St. Louis, MO, USA. All chemicals were of analytical grade and were used as received. A saline $0.15 \mathrm{ML}^{-1}$ Phosphate Buffer (PBS) at $\mathrm{pH}$ 7.5 was prepared by dissolving $0.2 \mathrm{~g} \mathrm{KCl}, 8.0 \mathrm{~g} \mathrm{NaCl}, 0.24 \mathrm{~g} \mathrm{KH} 2 \mathrm{PO} 4$ and $1.44 \mathrm{~g} \mathrm{Na}_{2} \mathrm{HPO}_{4} \cdot 2 \mathrm{H}_{2} \mathrm{O}$ in $1000 \mathrm{~mL}$ ultra-pure water. All solutions were prepared with deionized water.

\section{Instruments}

The bi-molecular interactions were investigated using a SPR system (Autolab Springle, Eco Chemie, Netherlands). SPR techniques involve the excitation of surface plasmons using a light source at planar surfaces. These techniques have been used extensively to characterize binding reactions without labeling requirements [13]. This equipment is based on the Kretschmann configuration, which is also the most commonly-used configuration in SPR. The planar gold SPR disks used were supplied with the instrument. The washing solutions were injected in the optical cell using a peristaltic pump at a flow rate of 1 $\mu \mathrm{l} / \mathrm{s}$. The flow of washing solution was programmed to stop during the incubation steps. The response of the immunosensor was automatically monitored using a PC with ESPRIT software version 4.4.

\section{Collection of KB-infected wheat seeds}

The KB infected wheat grains were obtained from Punjab Agriculture University, Ludhiana (Punjab) and Tarai Development Corporation, Haldi, Pantnagar.

\section{Collection of fungal spores/teliospores}

Spores and teliospores of seed borne pathogens (Tilletia foetida, Tilletia barclayana, Ustilago hordei and Ustilago virens) were collected from the Department of Plant Pathology, College of Agriculture, Pantnagar.

\section{Isolation of intact teliospores used as immunogen}

The intact teliospores were extracted as described previously [4,5] from the bunted seeds of wheat and used as a source of immunogen.

\section{Generation and Purification of anti-teliospore antibodies}

Albino, New Zealand white rabbits weighing $2 \mathrm{~kg}$ procured from IVRI, Bareilly were used for production of anti-teliospore antibodies. The animals were maintained in stainless steel cages at a room temperature of $22 \pm 2^{\circ} \mathrm{C}$ and free access to pellet food (Lipton India Ltd) and water. According to ethical regulations on animal research, all animals used in the experimental work received human care. The rabbits were immunized, by administering five injections at 10 days intervals with aliquots of intact teliosporic suspension $(0.4-0.5 \mathrm{ml})$ containing $500 \mu \mathrm{g}$ of teliospores emulsified with an equal volume of Freund's complete adjuvant for the first and incomplete adjuvant for the four subsequent injections. Ten days after the final injection, the blood was collected through cardiac puncture and the sera were kept at $-20^{\circ} \mathrm{C}$ [5]. Affinity purification of anti-teliospore antibodies was done using Protein A as affinity column (PIERCE, USA).

\section{Counting of spores/teliospores in suspension}

Spores/teliospores of various seed pathogens were suspended in the PBS at a concentration of $1 \mathrm{mg} / \mathrm{ml}$ after washing twice. Hemocytometer was used for counting the number of spores/teliospores in their respective suspension after making several dilutions. The counting was done after charging both the chambers of the hemocytometer after placing the cover slips and observing under Nikon wide field photomicroscope at $10 \mathrm{X} /$ magnification. The spores/teliospores were calculated according to the following expression:

Spores or teliospores $/ \mathrm{ml}=$ Average count per square $\times$ dilution factor $\times 10^{4}$.

\section{Solubilization of spores/teliospore}

The spores/teliospores were solubilized by chemical extraction method. Teliospore was mechanically lysed by grinding in liquid nitrogen $\left(\mathrm{Li} \mathrm{N}_{2}\right)$ in pestle and mortar. Extraction buffer $(0.5 \%$ SDS $)$ was added to further lyse spores and solubilize the protein. Once the spores have been lysed, the crude lysate centrifuged to remove the particulate debris, thereby leaving the protein of interest in supernatant solution. PMSF (Phenyl Methyl Sulfonyl Fluoride) at concentration of $2 \mathrm{mM}$ was added in supernatant solution and stored at $-20^{\circ} \mathrm{C}$.

\section{Development of indirect ELISA}

The indirect ELISA was developed on 96-well microtitre ELISA with minor modifications as described initially by Engvall and Perlmann [14] and modified in our lab. Microtitre plates were coated with varying concentration of teliospores ranging from 5 to 10,000 in coating buffer, i.e. $100 \mu \mathrm{l} /$ well. The plates were then incubated for $1 \mathrm{~h}$ at room temperature (approximately $22^{\circ} \mathrm{C}$ ), on a shaker for $1 \mathrm{~h}$ at $37^{\circ} \mathrm{C}$ and were kept overnight at $4-8^{\circ} \mathrm{C}$. The plates were washed with PBS. The wells were incubated with $2 \%$ BSA for $30 \mathrm{~min}$ for non-specific blocking, rinsed three times in PBS $+0.25 \%$ BSA. First antibody $(100 \mu \mathrm{l})$ was incubated for $2 \mathrm{~h}$ at room temperature and then the plate was washed with PBS $+0.25 \%$ BSA followed by incubation with 1:1000 diluted alkaline phosphatase conjugated goat anti-rabbit gamma globulin for $2 \mathrm{~h}$ at room temperature. It was again washed with PBS $+0.25 \%$ BSA three times. Alkaline phosphatase activity was assayed with p-nitro phenyl phosphate sodium salt. The reaction was stopped with $1.5 \mathrm{M} \mathrm{NaOH}$ solution and the color intensity was measured in ELISA plate reader at $405 \mathrm{~nm}$. 
Citation: Singh S, Singh M, Taj G, Gupta S, Kumar A (2012) Development of Surface Plasmon Resonance (SPR) Based Immuno-Sensing System for Detection of Fungal Teliospores of Karnal Bunt (Tilletia Indica), a Quarantined Disease of Wheat. J Biosens Bioelectron 3:125. doi:10.4172/2155-6210.1000125

Page 3 of 8

\section{Preparation of the Self-Assembled Monolayer (SAM)}

The cleaning of the bare gold surface is critically important for self-assembled monolayer formation and should be accomplished systematically. The gold disk was incubated in a 11 MUA solution (1 mM 11-Mercaptoundecanoic acid in ethanol) for overnight. The disk was washed three times with ethanol to remove excess thiol groups and three additional times with ultrapure water to remove the alcohol. The thiol covered sensor-disk was then used immediately or stored for later use. This sensor-disk was assembled on the hemi-cylinder by placing a small drop of immersion oil on the outer edge of the hemi-cylinder and gently sliding the sensor disk gold layer facing up from the start to the end of the hemi-cylinder. This step was carefully carried out to avoid introducing an air bubble between the gold sensor disk and the hemicylinder. The hemi-cylinder with the gold sensor disk was then inserted in the SPR machine. The cuvette was then placed in the cuvette holder to hold the hemi-cylinder together with the gold sensor disk.

Immobilization of anti-teliospore antibody on the Mercaptoundecanoic Acid (MUA) modified gold sensor chip

Immobilization of antibody on the SPR sensor chip comprises of eight steps. Prior to the immobilization of antibody on the Mercaptoundecanoic Acid (MUA) modified gold sensor chip was stabilized using PBS (Phosphate Buffer Saline). The resonance angle at this point was recorded as the baseline. In the first step, stabilization of baseline was carried out for $120 \mathrm{~s}$ in order to get a stable baseline signal. In the second step, activation of carboxyl groups on the SAM layer was performed for $600 \mathrm{~s}$ by injecting a $50 \mu \mathrm{l}$ solution of freshly prepared 1:1 mixture of EDC (400 $\mathrm{mM})$ and NHS $(100 \mathrm{mM})$ in distilled water over the chip surface in order to get more amine reactive NHS esters. In the third step, washing was conducted with PBS and the SPR angle shift nearly returned to the original baseline [15]. Subsequently, in the fourth step $50 \mu \mathrm{l}$ teliosporic antibody dilution of 1:250, 1:500, $1: 1000$ and 1:2000 was injected and allowed to react for $1800 \mathrm{~s}$ to get an effective immobilization of anti-teliosporic antibody over the activated MUA modified surface for each immunosensor response. Due to use of polyclonal purified antibody, the serum can contain several protein species. Consequently, to remove the unbound antibody from the modified sensor surface, in fifth step washing was performed. The specificity and sensitivity of such immunosensor towards the target antigen were further verified for its analytical performance. In the sixth step, to prevent non-specific binding of protein during SPR sensing and also to block the unreacted NHS ester groups on the sensor chip, $1 \mathrm{M}$ ethanolamine $(\mathrm{pH}=8.5)$ was injected and allowed to react for $600 \mathrm{~s}$ on the chip surface in order to deactivate unreacted NHS ester and also to overcome non-specific adsorption of protein on the chip surface during the sensing process. In the seventh step, washing was performed for $30 \mathrm{~s}$. After the antigen-antibody interactions $10 \mathrm{mM}$ $\mathrm{HCl}$ was injected in the eighth step, to achieve regeneration of the sensor surface. A solution of $10 \mathrm{mM}$ PBS ( $\mathrm{pH} 7.5$ ) was used throughout the experiment as the running buffer.

\section{Interaction of teliosporic wall antigen with the teliosporic antibody immobilized on sensor chip}

For affinity measurements of teliosporic antigen with immobilized anti-teliosporic antibody, varying concentration of teliosporic wall antigen dissolved in PBS was injected and then association was performed for $500 \mathrm{~s}$ and dissociation was performed for $400 \mathrm{~s}$. Subsequently, by adding $0.01 \mathrm{M} \mathrm{HCl}$ for $120 \mathrm{~s}$ antigen was recovered in order to bring the signal to baseline level so as to start a new measurement cycle. The above procedure was adopted with solutions containing 80 to $0.039 \mathrm{ng} / \mu \mathrm{l}$ concentration of teliosporic wall antigen.

\section{Results and Discussion}

\section{Effect of $\mathrm{pH}$ on SPR sensing}

The effect of $\mathrm{pH}$ on SPR angle due to interaction of teliosporic antigen with anti-teliosporic antibody immobilized on gold chip was performed (Figure 1). The experiments were conducted with a $2.5 \mathrm{ng} /$ $\mu \mathrm{l}$ antigen with the universal buffer mixture (PBS) in the $\mathrm{pH}$ range from 5.0 to 9.0. It was observed from figure 1 that the SPR angle increased with increase in $\mathrm{pH}$ upto 7.5 and then decreased at higher $\mathrm{pH}$. It is probably due to the $\mathrm{pH}$ dependent structural changes and electrostatic interactions of antigen and antibody that occurred on the sensor chip [16]. The results showed that interaction of teliosporic antigen-antiteliosporic antibody is more effective at $\mathrm{pH} 7.5$ and thereby resulted in more angle change, hence $\mathrm{pH} 7.5$ was chosen for further studies.

\section{Method versatility and reproducibility}

The activity and specificity of the surface was verified by simultaneously injecting teliosporic antigen over a blank surface and

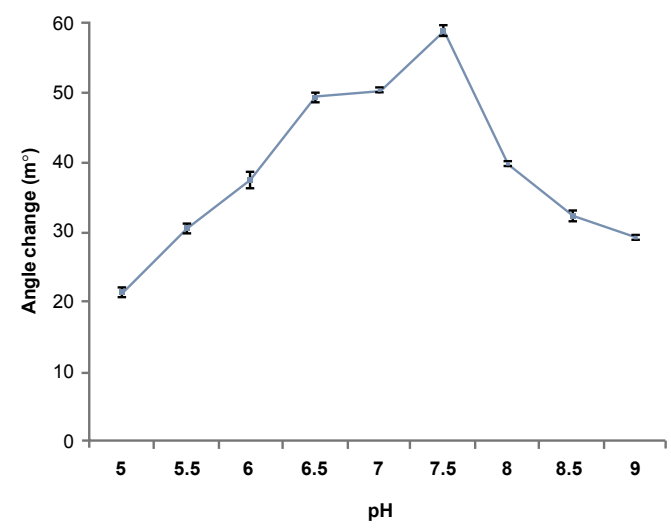

Figure 1: Effect of $\mathrm{pH}$ on the interaction of teliosporic antigen with immobilized antibody on the Mercaptoundecanoic acid (MUA) modified gold chip. $\mathrm{pH}$ range: $5.0-9.0$, and teliosporic antigen concentration: $2.5 \mathrm{ng} / \mathrm{\mu l}$.

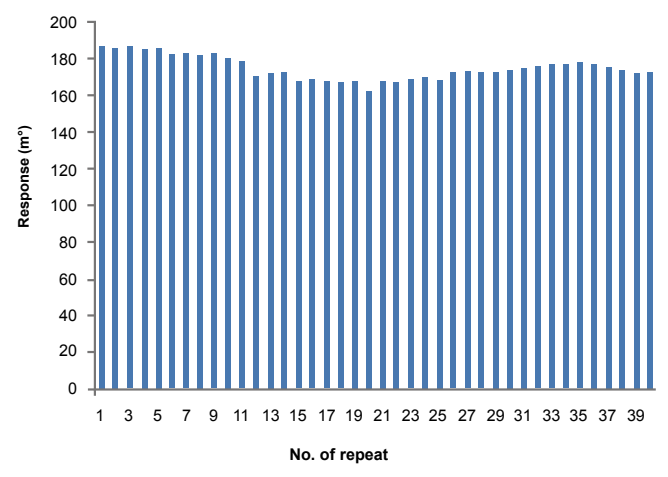

Figure 2: Surface reproducibility test for determination of stability of sensor surface by running several repeats of polyclonal antibody (after approximately 15 repeats the chip surface stabilized and following 40 injections, $7.7 \%$ decrease in surface activity was observed). 
Citation: Singh S, Singh M, Taj G, Gupta S, Kumar A (2012) Development of Surface Plasmon Resonance (SPR) Based Immuno-Sensing System for Detection of Fungal Teliospores of Karnal Bunt (Tilletia Indica), a Quarantined Disease of Wheat. J Biosens Bioelectron 3:125. doi:10.4172/2155-6210.1000125

Page 4 of 8

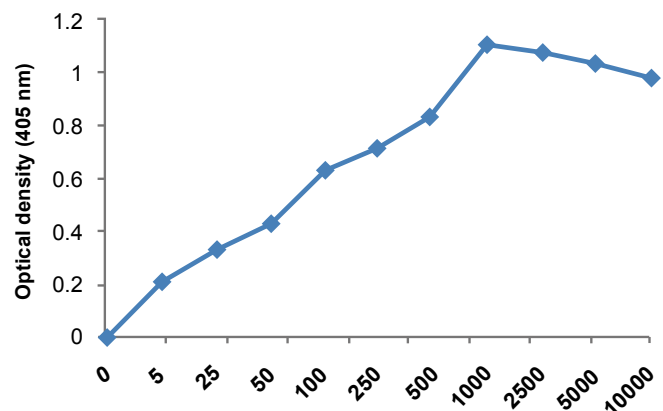

No. of Teliospores

Figure 3a: Determination of optimum number of teliospores by indirect ELISA using anti-teliospore antibodies.

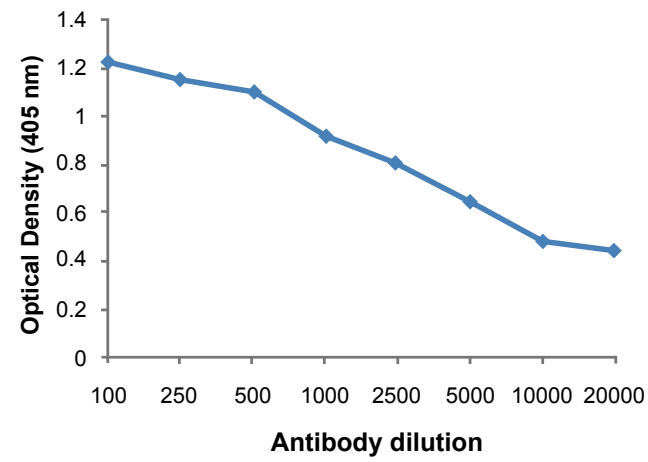

Figure 3b: Determination of optimum antibody dilution by indirect ELISA using Intact anti-teliospore antibody.

the functionalized surface (modified with antibody). No significant binding was observed on the blank surface compared to the surface functionalized with anti-teliospore antibodies. Method reproducibility was examined by running several repeats of polyclonal antibody and a single injection of $20 \mathrm{mM} \mathrm{HCl}$ was sufficient for surface regeneration. Following immobilization, sensor chip surfaces often need some initial cycles of regeneration to stabilize the surface before reproducible results can be obtained. This will increase the final cost of assays, but are necessary. After approximately 15 repeats the chip surface stabilized and following 40 injections, $7.7 \%$ decrease in surface activity was observed (Figure 2).

\section{Determination of sensitivity range of ELISA by Optimization of antigen and antibody concentration}

Indirect ELISA was performed to establish optimal antigen concentration. For antigen preparation, teliospore suspension $(1.0 \mathrm{mg}$ of teliospores $/ \mathrm{ml}$ of distilled water) was counted by haemocytometer and teliospore concentration was adjusted to: $2 \times 10^{5}$ teliospores per $\mathrm{ml}$. The wells of microtitre plate were coated with increasing number of teliospores ranging 5-10,000 as antigen in triplicate. For studying antigen concentration kinetics, primary and secondary antibodies were diluted at 1:500 and 1:1000 respectively. As evident from (Figure 3a), the OD 405 showed a linear increase upto 1000 teliospores after which the curve levelled off. In ELISA, highest value in linear relationship from the semi-log graph was recorded at 1000 teliospores and taken as optimum antigen concentration in indirect ELISA.

For determination of optimum dilution for antibodies, 1000 teliospores of antigen were coated in each well and various dilutions of anti-teliospore sera 1:100,1:250, 1:500, 1:1000, 1:2500, 1:5000, 1:10,000 and 1:20,000 were used. Using Karnal bunt teliospores and these dilutions, ELISA was observed and optimum dilution chosen as 1:250. The OD405 showed a linear decrease on increasing dilutions. A midpoint from the antibody dilution curve was selected and 1:250 was taken as optimum dilution of anti-teliospore antibody for further study (Figure 3b).

\section{Controlling immobilization level for development of immunosensor}

It is appropriate to reduce the amount of protein that is immobilized on the surface in order to avoid issues like mass transport limitations and avidity effects $[17,18]$. The influence of antibody concentration on immobilization level was examined. Different dilutions $(\mathrm{v} / \mathrm{v})$ of polyclonal serum containing the anti-teliosporic antibody (1:250, 1:500, 1:1000, and 1:2000) in $10 \mathrm{mM}$ sodium acetate at $\mathrm{pH} 4.5$ were tested (Figure 4a). By choosing the appropriate antibody dilution, the surface capacity could be carefully engineered. The result displayed in (Figure 3a) showed that the immobilization is indeed sensitive upto 1:2000 antibody dilution. The sensitivity of each immunosensor constructed with different dilutions of antibody was verified by injecting teliosporic antigen of $0.39-80 \mathrm{ng} / \mu \mathrm{l}$.

\section{Analysis of mass loading by anti-teliosporic immobilization on modified gold sensor chip}

SPR based biosensors have been widely used for the monitoring of various affinity bindings [19-24]. At lower concentrations (or larger dilutions), the sensitivity is reduced due to the low number of biomolecules adsorbed to the surface. For higher concentrations (or lower dilutions), the immobilized amount causes a slight decrease in the response (probably because of aggregate formation due to antibodyantibody interaction at high antibody concentrations), thereby reducing the sensitivity. In this context, an antibody of 1:500 dilution was selected for the subsequent experiments due to its good sensogram results. Using the SPR biosensor, the amounts of mass loading by anti-teliosporic antibody could be estimated. The mass loading was calculated from the baseline changes before and after sample injection.

A typical sensorgram for the stepwise immobilization of antiteliosporic antibody (1:500) over the modified gold SPR sensor chip is shown in figure $4 \mathrm{~b}$. Activation of carboxyl groups on the SAM allows the formation of highly reactive O-acylisourea intermediates [15] to promote the formation of amide bonds between the carboxylic acid groups of modified sensor chip and the amino groups of teliosporic antibody, during this process a large SPR angle shift of $459.2 \mathrm{~m}^{\circ}$ is observed. An increase in the SPR angle by $247.2 \mathrm{~m}^{\circ}$ is observed due to the immobilization of antibody. To remove the unbound antibody from the modified sensor surface washing was performed and during this process the SPR angle was decreased by $40.1 \mathrm{~m}^{\circ}$. Non-specific binding of protein was prevented during SPR sensing and also to block the unreacted NHS ester groups on the sensor chip. $1 \mathrm{M}$ ethanolamine was injected on the sensor chip, during this process an increase in SPR angle by $2051.8 \mathrm{~m}^{\circ}$ was observed. Washing was performed as discussed in the experimental part and a decrease by $1715.2 \mathrm{~m}^{\circ}$ in SPR angle was observed as a result of the removal of unbound ethanolamine. Regeneration was carried out for $120 \mathrm{~s}$ and a decrease by $1711.6 \mathrm{~m}^{\circ}$ in SPR angle is observed. The SPR response can be converted to a mass loading according to the relationship: $120 \mathrm{~m}^{\circ}=1 \mathrm{ng} / \mathrm{mm}^{2}$ [25]. According to this relation, an amount of $5.582 \mathrm{ng} / \mathrm{mm}^{2}$ of antibody was adsorbed on the sensor surface. 
Citation: Singh S, Singh M, Taj G, Gupta S, Kumar A (2012) Development of Surface Plasmon Resonance (SPR) Based Immuno-Sensing System for Detection of Fungal Teliospores of Karnal Bunt (Tilletia Indica), a Quarantined Disease of Wheat. J Biosens Bioelectron 3:125. doi:10.4172/2155-6210.1000125

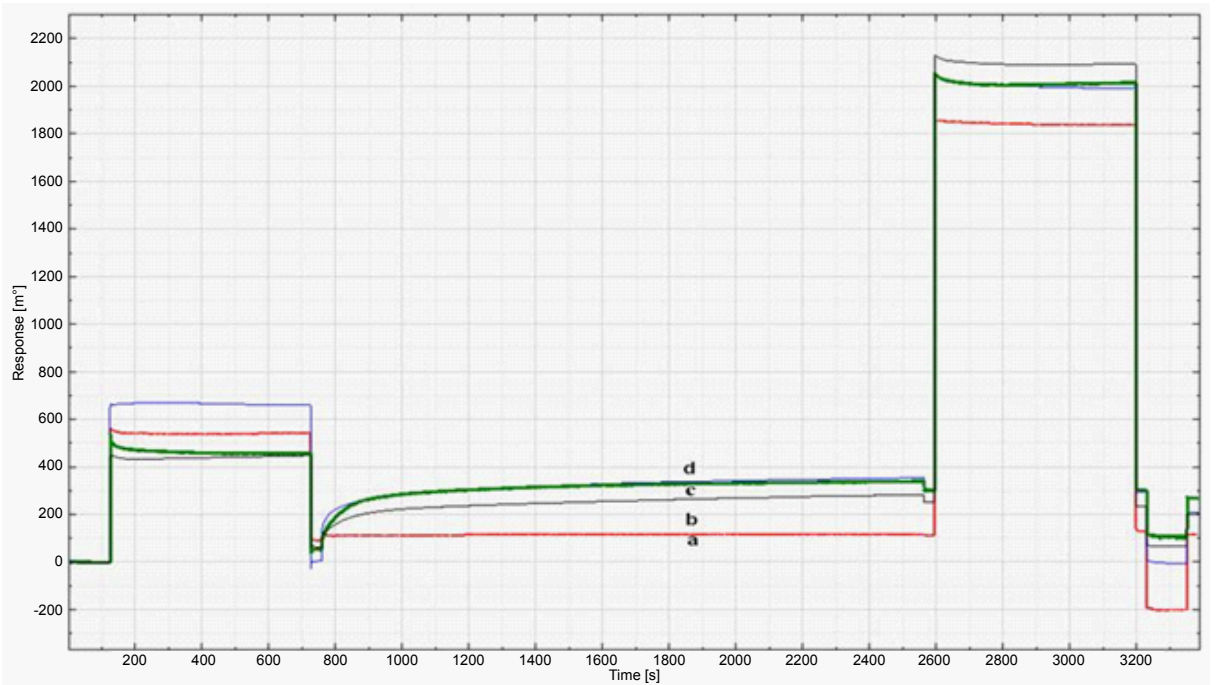

Figure 4a: Sensogram after immobilization of four dilutions of intact anti-teliosporic antibody a)1:2000; b)1:1000; C)1:500; d) 1:250

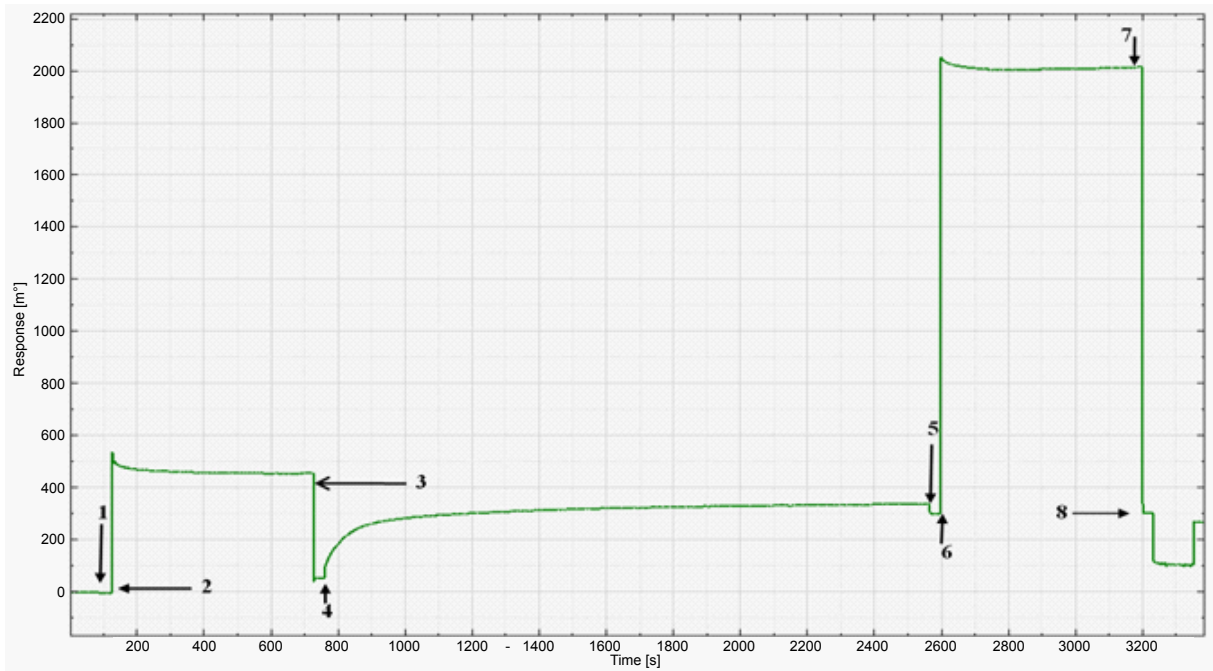

Figure 4b: Sensogram showing different steps involved in the immobilization of anti-teliosporic antibody (1:500): 1) Baseline, 2) EDC-NHS activation, 3) washing, 4) Ab coupling (Immobilization of Ligand) 5) washing, 6) Deactivation, 7) washing, 8) Regeneration.

\begin{tabular}{|c|c|c|c|c|c|c|c|c|c|}
\hline \multirow[t]{3}{*}{ No. of Spores } & \multirow[t]{3}{*}{ Ag conc. (ng/ul) } & \multicolumn{8}{|c|}{ Signal Response $\left(\mathrm{m}^{\circ}\right)$} \\
\hline & & \multicolumn{2}{|c|}{$1: 250(A b)$} & \multicolumn{2}{|c|}{$1: 500(\mathrm{Ab})$} & \multicolumn{2}{|c|}{$1: 1000(\mathrm{Ab})$} & \multicolumn{2}{|c|}{$1: 2000(\mathrm{Ab})$} \\
\hline & & Control & Sample & Control & Sample & Control & Sample & Control & Sample \\
\hline 320 & 80 & $12.8 \pm 0.34$ & $197.4 \pm 0.28$ & $6.1 \pm 0.43$ & $297.1 \pm 0.33$ & $12.3 \pm 0.28$ & $292.3 \pm 0.18$ & $10.2 \pm 0.28$ & $272.1 \pm 0.38$ \\
\hline 160 & 40 & $8.4 \pm 0.31$ & $158.4 \pm 0.33$ & $9.5 \pm 0.34$ & $259.5 \pm 0.24$ & $11.2 \pm 0.31$ & $251.2 \pm 0.31$ & $9.1 \pm 0.25$ & $211.2 \pm 0.54$ \\
\hline 80 & 20 & $9.1 \pm 0.21$ & $104.2 \pm 0.12$ & $6.4 \pm 0.31$ & $147.5 \pm 0.31$ & $12.2 \pm 0.21$ & $162.2 \pm 0.23$ & $11.6 \pm 0.34$ & $180.6 \pm 0.34$ \\
\hline 40 & 10 & $6.0 \pm 0.22$ & $96.5 \pm 0.22$ & $10.4 \pm 0.54$ & $107.4 \pm 0.51$ & $10.9 \pm 0.31$ & $118.9 \pm 0.37$ & $10.5 \pm 0.45$ & $70.4 \pm 0.26$ \\
\hline 20 & 5 & $6.6 \pm 0.19$ & $56.6 \pm 0.15$ & $11.1 \pm 0.46$ & $71.1 \pm 0.26$ & $11.6 \pm 0.31$ & $77.6 \pm 0.29$ & $8.5 \pm 0.64$ & $53.1 \pm 0.51$ \\
\hline 10 & 2.5 & $5.3 \pm 0.45$ & $33.6 \pm 0.31$ & $12.1 \pm 0.14$ & $51.1 \pm 0.34$ & $9.8 \pm 0.23$ & $40.8 \pm 0.34$ & $12.3 \pm 0.35$ & $35.4 \pm 0.34$ \\
\hline 5 & 1.25 & $8.1 \pm 0.29$ & $28.1 \pm 0.19$ & $10.6 \pm 0.33$ & $33.6 \pm 0.21$ & $6.4 \pm 0.32$ & $27.4 \pm 0.37$ & $8.8 \pm 0.33$ & $21.2 \pm 0.39$ \\
\hline 2.5 & .625 & $11.1 \pm 0.55$ & $23.1 \pm 0.51$ & $8.8 \pm 0.28$ & $18.8 \pm 0.16$ & $8.7 \pm 0.16$ & $30.7 \pm 0.29$ & $6.6 \pm 0.26$ & $18.5 \pm 0.62$ \\
\hline 1.25 & .312 & $12.9 \pm 0.23$ & $14.9 \pm 0.23$ & $12.3 \pm 0.27$ & $13.3 \pm 0.17$ & $7.9 \pm 0.33$ & $17.7 \pm 0.51$ & $9.3 \pm 0.51$ & $20.1 \pm 0.35$ \\
\hline .625 & .156 & $12.7 \pm 0.38$ & $12.7 \pm 0.16$ & $10.1 \pm 0.15$ & $11.1 \pm 0.14$ & $10.8 \pm 0.24$ & $10.8 \pm 0.46$ & $12.6 \pm 0.35$ & $16.9 \pm 0.53$ \\
\hline .312 & .078 & $12.8 \pm 0.17$ & $10.8 \pm 0.17$ & $11.8 \pm 0.49$ & $10.8 \pm 0.44$ & $8.2 \pm 0.22$ & $4.2 \pm 0.36$ & $10.9 \pm 0.28$ & $10.9 \pm 0.28$ \\
\hline .156 & .039 & $6.9 \pm 0.43$ & $11.9 \pm 0.40$ & $12.6 \pm 0.45$ & $7.3 \pm 0.42$ & $6.9 \pm 0.51$ & $3.8 \pm 0.27$ & $10.5 \pm 021$ & $7.3 \pm 018$ \\
\hline
\end{tabular}

Table 1: Signal response for the interaction of different concentrations of teliosporic antigen with 4 different dilutions of control and immobilized anti-teliosporic antibody. 
Citation: Singh S, Singh M, Taj G, Gupta S, Kumar A (2012) Development of Surface Plasmon Resonance (SPR) Based Immuno-Sensing System for Detection of Fungal Teliospores of Karnal Bunt (Tilletia Indica), a Quarantined Disease of Wheat. J Biosens Bioelectron 3:125. doi:10.4172/2155-6210.1000125

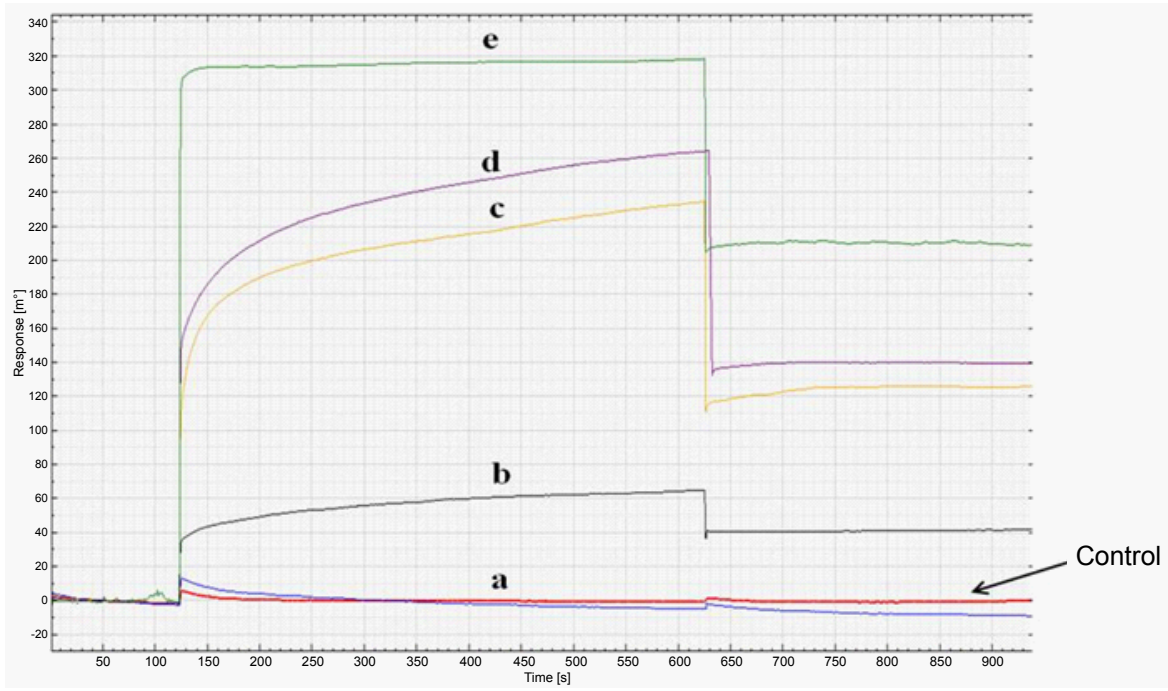

Figure 4c: SPR sensor response after the interaction of different concentrations (a) $.312 \mathrm{ng} / \mu \mathrm{l}$, (b) $1.25 \mathrm{ng} / \mu \mathrm{l}$, (c) $5 \mathrm{ng} / \mu \mathrm{l}$, (d) $20 \mathrm{ng} / \mu \mathrm{l}$, (e) $80 \mathrm{ng} / \mu \mathrm{l}$ of antigen over the immobilized antibody (1: 500).

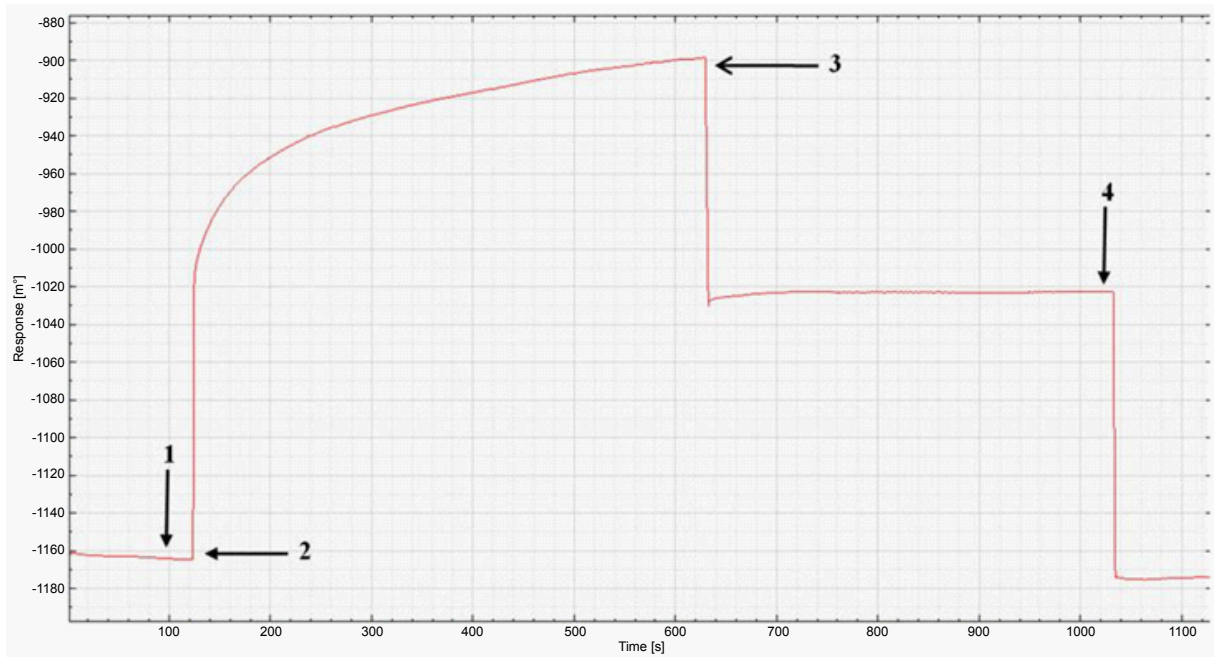

Figure 4d: SPR sensor response after the interaction of $20 \mathrm{ng} / \mu \mathrm{l}$ teliosporic antigen: 1) baseline; 2) association; 3) dissociation and 4) regeneration over the immobilized antibody.

Interaction of teliosporic wall antigen with the antiteliosporic antibody immobilized on sensor chip

The interaction of antigen at a concentration of $80,40,20,10,5.0$, $2.5,1.25,0.625,0.312,0.156, .078$ and $.039 \mathrm{ng} / \mu \mathrm{l}$ over the each dilution of immobilized antibody was examined (Table 1). The sensogram for the interaction of different concentration of teliosporic antigen $(0.39-80$ $\mathrm{ng} / \mu \mathrm{l}$ ) over the teliosporic antibody immobilized sensor chip is given in figure $4 \mathrm{c}$. The responses increased in proportion to the concentration of teliosporic antigen due to the change of the refractive index near the SPR sensor chip. As shown in table 1, there is practically no decrease in the signal below the concentration of $2.5 \mathrm{ng} / \mu \mathrm{l}, 0.625 \mathrm{ng} / \mu \mathrm{l}, 1.25$ $\mathrm{ng} / \mu \mathrm{l}$ and $1.25 \mathrm{ng} / \mu \mathrm{l}$ over the immobilized antibody dilution of 1:250, $1: 500,1: 1000$, and 1:2000 respectively. A full sensogram of interaction of $20 \mathrm{ng} / \mu \mathrm{l}$ teliosporic antigen is given in figure $4 \mathrm{~d}$ which includes, 1) baseline; 2) association; 3) dissociation and 4) regeneration. After regeneration step the signal was returning to baseline. The sensitivity of SPR assay was found to be $625 \mathrm{pg}$ of teliosporic wall antigen which is equivalent to the numbers of 2.5 intact teliospores by using 1:500 anti-teliosporic antibody dilutions. Further using SPR, the analysis is faster and there is the possibility of signal observation in real-time and label-free mode.

\section{Cross-reactivity studies}

In order to determine the specificity of SPR based immunodetection system solubilised antigens of spores/teliospores of different fungal species were used. Solubilized antigens over the anti-teliosporic antibody (1:500 dilution) of immobilized on sensor chip as described above. The ability of anti-teliosporic antibody to discriminate between related bunt and smut fungi was investigated using SPR. The interaction of antibody with bunt species (Tilletia foetida and Tilletia barclayana) and smut species (Ustilago hordei and Ustilago virens) were tested, Ustilago hordei showed weak reactivity while Tilletia barclayana showed the high reactivity (Figure 5). The interaction of anti-teliospore antibody with other fungal species is due to binding 

for Detection of Fungal Teliospores of Karnal Bunt (Tilletia Indica), a Quarantined Disease of Wheat. J Biosens Bioelectron 3:125. doi:10.4172/2155-6210.1000125

Page 7 of 8

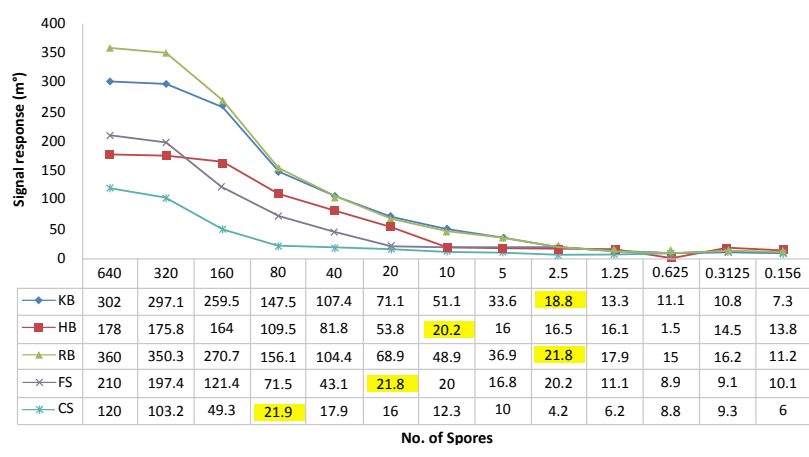

Figure 5: Cross-reactivity studies of anti-teliospore antibody with other bunt and smut fungal spores using SPR (KB: Tilletia indica; RB: Tilletia barclayana; HB: Tilletia foetida, CS: Ustilago hordei ; FS: Ustilago virens).

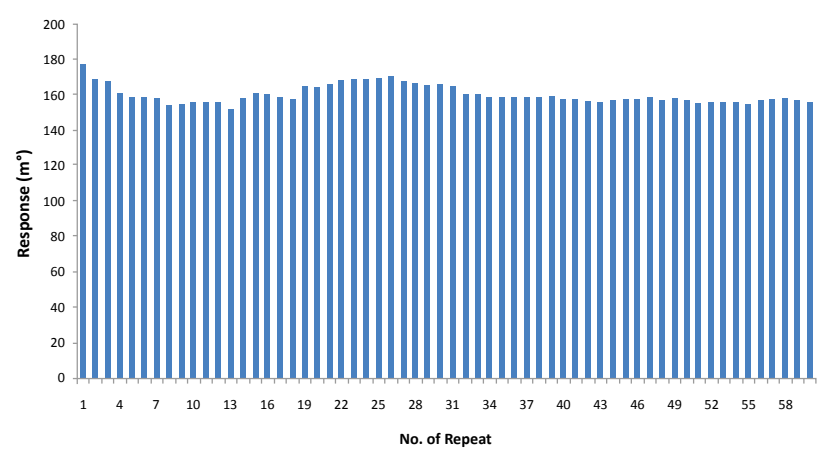

Figure 6: Surface regeneration for determination of long term stability of sensor surface after several repeats of target antigen (after approximately 19 regenerations the chip surface stabilized and following 60 injections, a decrease in surface activity of $12.3 \%$ was observed).

affinity with common antigen displayed on fungal spores/teliospores. The sensitivity of this test was found to be 80-0.625 ng of solubilized teliosporic wall antigen equivalent to 320-2.5 numbers of intact teliospores of $T$. indica. The sensitivity of this immunosensing system with other fungal spores/teliospores is less while comparing with teliospores of Karnal bunt. As shown in figure 5, the signal response decreased in response to decreasing teliosporic protein concentrations, thereby demonstrating that anti-teliosporic antibody is capable of specifically detecting KB. The results in this study clearly demonstrate that the biosensor approach is superior in terms of analysis time, automation, and sensitivity. Interaction time was approximately 21 min, which includes baseline, association (measurement of binding response), dissociation and regeneration.

The immunosensor was able to discriminate between bunt and spores from related smut fungi species and therefore exhibits a comparable selectivity to the reported immunological based method. Furthermore, as the present sensor is label-free and no sample extraction or data processing is needed, it is more suitable for future fast on-site analyses. The generic biosensor setup described in this paper could feasibly be used for detection of any fungal spore, the only requirement being the availability of a suitable antibody specifically recognizing only corresponding target antigens. Various specific antibodies, including polyclonals, monoclonals and single-chain Fv antibody fragments ( $\mathrm{scFv}$ ), have been developed against multiple important fungal and fungal-like spore species [26-28]. By immobilising a suitable capture molecule on the sensor chip, such as an anti-isotype antibody, anti-
Fab antibody or protein A/G affinity purified antibody, all available as pathogen specific antibodies can potentially be used for label-free detection using the approach described in this paper.

\section{Surface regeneration}

To examine the regeneration of the surface, rabbit polyclonal antibody was immobilized on sensor surface. Regeneration over the immobilized antibodies was examined by running 60 repeats of teliosporic antigen and the surface was effectively regenerated using $250 \mu \mathrm{l}$ of $10 \mathrm{mM} \mathrm{HCl}$ at a flow rate of $10 \mu \mathrm{l} / \mathrm{min}$. After approximately 19 regenerations the chip surface stabilized and following 60 injections, a decrease in surface activity of $12.3 \%$ was observed (Figure 6).

\section{Conclusion}

This paper describes an optimization of SPR based immunosensing system for KB diagnosis using anti-teliosporic antibody (1:500 dilution) immobilized on a SAM. A label free real time SPR detection methodology for fungal teliospore detection was developed using a sensor chip. The $\mathrm{pH}$ of universal buffer for the antigen-antibody interaction was determined for detection of $\mathrm{KB}$ in order to avoid crop damage. This device showed that is possible to achieve the detection of Karnal Bunt to avoid crop damage. The sensitivity is $625 \mathrm{pg}$ which is equivalent to as small as 2.5 teliospores. Under optimized assay conditions as few as 5 teliospores were detected by ELISA. Furthermore, the assay could discriminate $\mathrm{KB}$ pathogen from other related bunt (T. foetida and T. barclayana) and smut species (Ustilago hordei and Ustilago virens) based on signal response. Due to the simplicity of the sensor set up presented here, even non-plant pathologists will be able to detect $\mathrm{KB}$ with high confidence. This biosensor represents the first demonstration of SPR technology for KB detection in order to identify the teliospores of contaminating fungus in wheat lots, which could be used by the seed certification lab and plant quarantine department. The performance of the method reported in the study was adequate to perform a rapid, easy and reliable analysis. The great advantage in using SPR as a transducer system is the ability to carry out an immunoassay without needing a tracer, thereby reducing the response time and making it possible to monitor immune-complex formation.

\section{Acknowledgement}

The authors wish to acknowledge the Department of Science and Technology (DST), Govt. of India for providing financial support. The authors are also grateful to Dean, College of Basic Sciences and Humanities, and Director, Experiment station for providing all necessary help and facilities for carrying out this research.

\section{References}

1. Mitra M (1931) A new bunt on wheat in India. Ann Appl Biol 18: 178-189.

2. Kumar A, Singh US, Kumar J, Garg GK (2008) Application of molecular and immunodiagnostic tools for detection, surveillance and quarantine regulation of Karnal bunt (Tilletia indica) of Wheat. Food Agric Immunol 19: 293-31.

3. Mishra A, Kumar A, Garg GK, Sharma I (2001) Determination of Genetic Variability among Isolates of $T$. indica using Random Amplified Polymorphic DNA analysis. Plant Cell Biotechnology and Molecular Biology 1: 29-36.

4. Gupta V, Kumar A, Lakhchaura BD, Garg GK (2001) Generation of antiteliospores antibodies for immunolocalization and characterization of antigenic epitopes of teliospores of Karnal bunt (Tilletia Indica) of wheat. Indian J Exp Biol 39: 686-690.

5. Kumar A, Singh A, Garg GK (1998) Development of Seed Immunoblot Binding Assay for Detection of Karnal bunt (Tilletia indica) of Wheat. Journal of Plant Biochemistry and Biotechnology 7: 119-120.

6. Gupta V, Kumar A, Singh A, Garg GK (2000) Immunodetection of teliospores of Karnal bunt (Tilletia indica) of wheat using fluorescent staining tests. Plant Cell Biotechnology and Molecular Biology 1: 81-86. 
Citation: Singh S, Singh M, Taj G, Gupta S, Kumar A (2012) Development of Surface Plasmon Resonance (SPR) Based Immuno-Sensing System for Detection of Fungal Teliospores of Karnal Bunt (Tilletia Indica), a Quarantined Disease of Wheat. J Biosens Bioelectron 3:125. doi:10.4172/2155-6210.1000125

Page 8 of 8

7. Kesari RE, Kumar A (2003) Design and Optimization of novel Immuno-dipstic test for detection of teliospores of Karnal Bunt (Tilletia indica) of wheat. Indian J Biotechnol 2: 603-606.

8. Kesari R, Mishra DP, Garg GK, Kumar A (2005) Suitability of dyed latex bead agglutination test for immunodiagnosis of Karnal bunt (Tilletia indica) teliospores in a single seed of wheat. Food Agric Immunol 16: 73-81.

9. Pumera M, Sanchez S, Ichinose I, Tang J (2007) Electrochemical Nanobiosensors. Sens Actuators B Chem 123: 1195-1205.

10. Vo-Dinh T, Cullum B (2000) Biosensors and biochips: advances in biological and medical diagnostics. Fresenius J Anal Chem 366: 540-551.

11. Hoa XD, Kirk AG, Tabrizian M (2007) Towards integrated and sensitive surface plasmon resonance biosensors: a review of recent progress. Biosens Bioelectron 23: 151-160.

12. Marquette CA, Blum LJ (2006) State of the art and recent advances in immunoanalytical systems. Biosens Bioelectron 21: 1424-1433.

13. Lin LP, Huang LS, Lin CW, Lee CK, Chen JL, et al. (2005) Determination of Binding Constant of DNA-binding Drug to Target DNA by Surface Plasmon Resonance Biosensor Technology. Curr Drug Targets Immune Endocr Metabo Disord 5: 61-72.

14. Engvall E, Perlmann P (1971) Enzyme-linked immunosorbent assay (ELISA) Quantitative assay of immunoglobulin G. Immunochemistry 8: 871-874.

15. Paynter S, Russell DA (2002) Surface plasmon resonance measurement of $\mathrm{pH}$-induced responses of immobilized biomolecules: conformational change or electrostatic interaction effects? Anal Biochem 309: 85-95.

16. Christensen LL (1997) Theoretical analysis of protein concentration determination using biosensor technology under conditions of partial mass transport limitation. Anal Biochem 249: 153-164.

17. Myszka DG (1997) Kinetic analysis of macromolecular interactions using surface plasmon resonance biosensors. Curr Opin Biotechnol 8: 50-57.
18. Suratini E, Sollier E, Calemczuk R, Livache T, Marche PN, et al. (2007) Realtime detection of lymphocytes binding on an antibody chip using SPR imaging Lab Chip 7: 1206-1208.

19. Teramura Y, Iwata H (2007) Label-free immunosensing for alpha-fetoprotein in human plasma using surface plasmon resonance. Anal Biochem 365: 201-207.

20. Battaglia TM, Masson JF, Sierks MR, Beaudoin SP, Rogers J, et al. (2005) Quantification of cytokines involved in wound healing using surface plasmon resonance. Anal Chem 77: 7016-7023.

21. Lung FD, Chen CH, Liou CC, Chen HY (2004) Surface plasmon resonance detection of interactions between peptide fragments of $\mathrm{N}$-telopeptide and its monoclonal antibodies. J Pept Res 63: 365-370.

22. Yang CY, Brooks E, Li Y, Denny P, Ho CM, et al.(2005) Detection of picomolar levels of interleukin-8 in human saliva by SPR. Lab Chip 5: 1017-1023.

23. Ricci F, Volpe G, Micheli L, Palleschi G (2007) A review on novel developments and applications of immunosensors in food analysis. Anal Chim Acta 605: 111129.

24. Tsai WC, Li IC (2009) SPR-based immunosensor for determining staphylococcal enterotoxin A. Sens Actuators B Chem 136: 8-12.

25. Stenberg E, Persson B, Roos H, Urbaniczky CJ (1991) Quantitative determination of surface concentration of protein with surface plasmon resonance using radiolabeled proteins. J Colloid Interface Sci 143: 513-526.

26. Bossi R, Dewey FM (1992) Development of a monoclonal antibody immunodetection assay for Botrytis cinerea. Plant pathology 41: 472-482.

27. Gough KC, Li Y, Vaughan TJ, Williams AJ, Cockburn W, et al. (1999) Selection of antibodies to surface epitopes of Phytophthora infestans. J Immunol Methods 228: $97-108$

28. Werres S, Steffens C (1994) Immunological techniques used with fungal plantpathogens: aspects of antigens, antibodies and assays for diagnosis. Ann App Biol 125: 615-643 